\title{
Educating students and their future employers to minimise environmental and climate impacts through cost effective environmental management strategies.
}

Kay Emblen-Perry, Worcester Business School, University of Worcester, Worcester, WR1 3AS, UK. k.emblenperry@worc.ac.uk

Les Duckers, Coventry University, Coventry, CV1 5FB, UK. L.Duckers@coventry.ac.uk

\begin{abstract}
Traditionally, internal views from UK businesses expect the maximisation of profits and delivery of value for the customer; the external view expects realistic profits and provision of employment. However, this view is changing, with customers increasingly demanding products and services that also demonstrate environmental responsibility and minimise climate impacts.
\end{abstract}

Although the cause-effect relationship between business operations, negative environmental impacts and climate change is well established there is now an enhanced appreciation that environmental challenges are systemic, interlinked and cannot be addressed in isolation.

Despite the proliferation of 'low cost' or 'no cost' technological and behavioural opportunities, businesses struggle to realise opportunities that address these interlinked challenges, demonstrate environmental responsibility and minimise climate impacts, as they are embedded in economic systems in which improvement equals investment. Environmental improvement interventions have become synonymous with cost consumption rather than cost saving; frequently at odds with corporate financial strategies.

In an attempt to change this view, support the mitigation of climate change through the reduction of environmental impacts and develop successful employment-ready graduates skilled in effective environmental improvement techniques, an innovative Environmental Strategy Module engaging postgraduate students in environmental management strategy design is taught at Coventry University. This offers students a more financially accessible approach to environmental improvement: a self-funding environmental management strategy created through the Environmental Value for Money Framework.

This paper presents a conceptual study of the Environmental Value for Money Framework and its engagement of students as future employees in creating self-funded, economically viable environmental management strategies. It also offers this framework as a mechanism to encourage businesses to engage in carefully planned and economically viable strategic environmental improvements.

Key words: Environmental management strategy, environmental responsibility, environmental impacts; Environmental Value for Money Framework

\section{Introduction}

Over the last 3 decades, there has been a growing recognition from pressure groups, trade organisations, politicians and the public of the need to rethink businesses' role on creating sustainable futures. Firstly, there is an acknowledgement that organisations can severely affect climate change through their day-to-day operations and therefore need to minimise 
their environmental impacts (Finke, Gilchrist and Mouzas 2016; Carbon Trust 2015). Secondly, as highlighted within the Sustainable Development Goals (SDG) 4 and 12 there is a growing expectation that educational systems should contribute to developing a sustainable society (United Nations 2017). UNESCO (2017) argues that the momentum for Education for Sustainability (EfS) has never been stronger but to achieve the development of skills, values and attitudes required to develop sustainable futures, education systems must introduce pedagogies that empower learners to transform the way they think and act.

The understanding of the cause-effect relationships of environmental challenges from the use of natural resources, generation of waste and creation of environmental pollution (which are key environmental impacts of businesses) and climate change has evolved in recent years. It is now generally accepted that these challenges are systemic in nature and cannot be tackled in isolation (European Environment Agency 2015). This paper therefore supports the mitigation of climate change by provoking environmental impact reduction.

Although there is widespread external pressure for organisations to demonstrate environmental responsibility, a positive, proactive response has not been forthcoming across all UK commercial sectors. Whilst it has become normal for large UK organisations to recognise their actual and/or potential environmental impacts and implement a strategic response, it is still uncommon for SMEs to adopt formal environmental management strategies (Graafland and Smid 2016). Rather, where environmental responsibility is accepted, it is more usual for SMEs to adopt an ad hoc approach to reduce and mitigate environmental impacts (Panwar et al. 2016).

During the authors' attempts to recruit smaller companies for a previous student led, live environmental audit project, it was recognised that whilst many businesses expressed an interest in minimising their impact on the environment very few were familiar with environmental management practices or how to implement environmental improvement processes. Cassells and Lewis (2017) found a similar lack of engagement with environmental management strategies despite growing expectations from stakeholders to behave environmentally responsibly and adopt principles and practices of environmental management. Larger organisations generally recognise that management systems, auditing processes and certification schemes (e.g. ISO14001, ISO50001, EMAS) offer tested approaches for improving environmental sustainability performance that can give them a badge of environmental responsibility.

However, there is a lack of appropriately trained staff to drive the sustainability agenda within organisations, which is reducing their ability to contribute to environmental protection and minimise climate impacts. EfS has lagged behind the sustainability interests of businesses (Benn and Dunphy (2009); Lambrechts and Ceulemans, 2013) so that management curricula have not adequately prepared students to deal with sustainability issues (Waddock 2009). This growing sustainability skills gap has left only $13 \%$ of UK organisations possessing the skills required to compete successfully in a sustainable economy (IEMA 2014). Universities are now playing an increasingly important role in closing this skills gap, with increasing resource invested in enhancing graduate employability (Cashian, Clarke and Richardson 2015) and adopting real world settings within learning and teaching (Wiek et al. 2014) to develop employment ready graduates.

In response to this demand for environmentally literate students and to potentially reduce the environmental impacts of businesses, the authors have designed an innovative postgraduate Environmental Strategy Module that is an integral part of the Environmental Management MSc at Coventry University. It focuses learning, teaching and assessment (LTA) around the creation of a pro-active, self-funded five-year environmental management strategy for a 
simulated business utilising the Environmental Value for Money Framework (EVFM Framework). This engages students in a real-world scenario to enhance EfS and feed forward practical skills that are able to reduce environmental impacts through cost effective environmental management strategies to their future employers.

This paper presents a conceptual study of a practical approach to EfS that contributes to the minimisation of environmental impacts that are linked to climate change; energy consumption, pollution and use of natural resources. It explores the Environmental Management Strategy Module, with a particular focus on the EVFM Framework as a dualpurpose tool. Firstly, a learning, teaching and assessment approach generates academic success through the engagement of students in environmental strategy design in a simulated real world setting. Secondly, it facilitates an innovative methodology for environmental management strategy design for organisations seeking a cost effective approach to environmental improvements. This self-funded approach to environmental strategy design is particularly valuable for organisations that do not currently benefit from the value for money environmental improvement interventions that are widely available as they expect them to require initial financial investment. The authors have linked these two aspects of the EVFM Framework to provide a 'feed forward' experience for students who can take this knowledge and academic experience into their business careers.

This paper adds to the discourse on LTA for EfS and offers experience-based guidance to other educators implementing active learning in real-world settings. It also offers a tool that may help mitigate climate change by provoking environmental impact reduction.

\section{Environmental Management Strategy in an Organisational Context}

An Environmental management strategy is important as it allows an organisation to contribute to sustainable development through the application of environmental management processes (Shrivastava and Shrivastava 1995). Benefits from adopting an environmental management strategy include cost savings, reduction of risk, increased stakeholder engagement and demonstration of responsibility (Fothergill, Smith and Payne 2017), regulatory compliance (Khalili and Duecker 2013) and more market focused benefits such as client demands and image benefits (Potoski and Prakash 2004; Campos 2012).

Environmental audits are a fundamental part of an environmental management strategy. These voluntary, essential management procedures allow organisations to detect problems before they effect operations (Beckett and Murray 2000), develop systematic approaches to improving environmental performance (Hillary 2004), avoid or manage environmental harm whilst improving economic performance (Viegas et al. 2013) and provide a benchmark from where to measure subsequent change (Clark 1998).

Whilst it is normal for large organisations to have an environmental management strategy, conduct environment audits and possibly obtain accreditation, most smaller companies in the UK appear reluctant to adopt such strategic approaches so that many environmental issues remain peripheral to the day-to-day running of the business (Studer et al. 2008). Khalili and Duecker (2013) consider financial constraints the key to this disengagement and suggest the biggest challenge facing organisations is access to resources to support the development of an environmental management strategy. They highlight the limiting effects of the conflict of maximising financial performance whilst minimising negative environmental impacts. The perception of intervention costs, rather than their reality, may also act as a barrier to formal environmental management (Ervin et al. 2012). Reluctance to engage formally in environmental management may also involve cultural barriers and challenges. Large (2012) 
suggests accreditation forces a specific approach to environmental improvement that may not suit a number of businesses, particularly SMEs.

An environmental management strategy can contribute to the achievement of Sustainable Development Goals 9 and 12 that promote the adoption of sustainable practices so that organisations do more and better with less (United Nations 2017). SDG 12 advocates awareness-raising, education and the provision of adequate information to encourage sustainable production while SDG 9 supports the achievement of environmental objectives through technological progress (United Nations 2017). An environmental audit as part of an environmental management strategy also supports the adoption of sustainability reporting promoted by SDG 12. However, the lack of a standardised framework to integrate environmental excellence into a business strategy discourages the adoption of strategic interventions to minimise climate impacts.

\section{Environmental Management Strategy in a Learning, Teaching and Assessment Context}

Both students and their potential employers now expect academics to promote employment skills within LTA (Pegg et al. 2012) so that employment-ready graduates and postgraduates with environmental sustainability knowledge and appropriate employability skills are able to join organisations after completing their studies. This contributes to the achievement of SDG 4, which targets all learners to have relevant skills for employment and the knowledge and skills needed to promote sustainable development (United Nations 2017). The promotion of employment skills within Higher Education (HE) is particularly important in the UK, as 85\% of graduate roles now require environmental sustainability knowledge (Drayson 2014). However, an environmental skills gap exists and in many cases the environmental knowledge of the graduates does not meet business needs (Laurinkari and Tarvainen 2017).

Alongside the need for environmentally literate employees, students' preferences for interactive, experiential learning have also reshaped the practice of Education for Sustainability (EfS) in HE (HEFCE 2013; Higher Education Academy 2016). Together these are replacing traditional instructivist approaches to learning, teaching and assessment with participatory and collaborative user interactions (Conole and Alevizou 2010).

The need for sustainability advocates and drive for sustainable futures requires more integrated and practical solutions that engage future sustainability professionals in proactive actions rather than reactive resolutions. However, EfS programmes frequently exclude such proactive approaches to the inherently complex environmental sustainability (Viegas et al. 2016). Ferreria, Lopes and Morais (2006) suggest this pro-active, integrated learning develops by combining environmental management with project-based learning to provide a holistic view of reality.

The inclusion of an environmental management strategy project as a LTA methodology provides a significant opportunity to develop students' theoretical and practical work. This stimulates self-directed learning (Moalosi, Molokwane and Mothibedi 2012), increases integrated thinking which creates knowledge through collating and synthesising information (Nonaka 1994) and enhances softer employment skills such as commitment and responsibility (Ferreria, Lopes and Morai 2006). Crossthwaite et al. (2006) suggest these generic and transferable employability skills are more likely to develop when students engage with realistic and relevant experiences in contexts that they find meaningful.

Oblinger and Oblinger (2005) and Wiek (2014) emphasise the importance of educating students in real-world settings. This learning, teaching and assessment approach is intended to trigger students' thinking, which develops learning for insight (Beech and MacIntosh 
2012) and challenge preferences for just-in-time learning to achieve the long term transformation rather than short term victories advocated by Sharp (2012). The authors consider that utilising a company brief driven environmental management strategy assignment immerses students in real-world project-based and solution orientated learning and supports the positive outcomes of 'learning by doing'; engaging students (Dewey 1916) and complex problem solving (Wiek et al. 2014). Corcoran and Walls (2004) recognise that an audit project is both an outcome and a process of learning.

\section{The Design of the Study}

This conceptual study focuses on the authors' experiences of the creation and application of an innovative, cost-effective environmental management strategy that has been adopted as the LTA methodology for the postgraduate Environmental Strategy Module. It makes use of observations of students in-class and post-study applications of the EVFM Framework and analysis tools provided to support in-class and assignment activities. Secondary research has been undertaken to provide the evidence base for the strategic interventions presented in the EVFM Framework example. The authors have undertaken this research to offer other educators in the sustainability community a practical tool for EfS that may encourage students' long-term transformation to successful environmental practitioners and sustainability advocates and provide practical support to organisations seeking cost-efficient environmental improvement opportunities.

\section{Environmental Management Strategy in the Module Context}

The Environmental Strategy Module forms a fundamental part of the Environmental Management MSc, providing vital sustainability knowledge, skills and values and practical employment skills to promote environmental responsibility within individuals and organisations. The authors aim to encourage students to develop an individual and collective sense of responsibility that Burgess (2006) and Ellison and Wu (2008) consider able to motivate learning for good practice. The authors designed the module to introduce students to the opportunities available to organisations that can minimise climate impacts through cost effective environmental management strategies. This learning, teaching and assessment approach aligns with the SDGs, which advocate utilising resources more effectively and doing more and better with less (United Nations 2017). It is the authors' intention to train students in the use of tools and techniques and develop environmental knowledge, skills and values that can feed forward into their future workplaces to provoke environmental responsibility and climate action.

The module runs in six, 4-hour sessions held weekly. Each session includes the foundation knowledge of business sustainability appropriate for postgraduate students, practical activities to promote the integration and synthesis of this information and exploration of potential solutions to emerging issues. This enables students to explore the effect of sustainable and unsustainable behaviours on businesses, particularly their internal and external pressures from and impacts on stakeholders. The authors also provide audit process and skills training throughout the module in formal and informal training sessions.

The module assignment comprises of two elements; firstly, students are required to undertake an environmental audit of the simulated, real-life company presented in the form of a mixedmedia case study and secondly they utilise the audit findings to design a five-year self-funded environmental management strategy utilising the EVFM Framework. Within this, the students are required to generate an Environmental Fund to create a budget to pay for larger 
interventions that can generate more significant mitigation impacts and financial savings. Whilst students create a theoretical environmental management strategy, the approach is equally valid for real-world organisations.

In preparation for the module's taught sessions and assignment, each student receives a company briefing document that contains a detailed profile of a simulated real-life engineering company based in the UK's West Midlands region. This company brief includes mixed media information (text, photos, data sheets etc.) on the company's size, history and operational activities, including supply chain transport and material handling. In order to complete an effective environmental audit, the results of which provide baseline data for the EVFM Framework, the student is able to request additional information in an 'audit meeting' in which one of the authors acts as the company's auditee. Additional company data requested typically includes site plan, energy consumption and utility bills, raw materials purchased, waste quantities, environmental incidents, stakeholder complaints and chemical storage. The authors note that they do not provide a split of energy data between heating and process energy to engage students in tools and techniques for energy consumption analysis such as Degree Day Analysis.

The student undertakes a detailed environmental audit of the simulated company utilising the company brief and information obtained from the audit meeting. Their audit can identify areas of good practice, detect problems and provide the benchmark from which to recommend subsequent strategic change. This audit, the initial part of the assignment, then feeds forward into the assessed five-year improvement strategy for the case study company.

As part of the in-class support, the authors present additional environmental performance analysis tools and techniques to assist students design the 'no-cost' foundation year of their strategy. Examples of these tools are presented within the interventions explored below. Undertaking and understanding the value of more detailed performance evaluation can raise awareness, educate and encourage both students and organisations to measure and analyse their own performance. This can, in turn, enhance organisational performance improvement and provoke sustainability reporting in line with the aims of SDG 12. The incorporation of investment in environmentally sustainable technologies in the environmental management strategy supports SDG9.

The authors take this self-funded approach to strategic environmental management to demonstrate that environmental performance can be improved without relying on fixed and variable asset budgets that could be used elsewhere within an organisation to improve competitiveness. The 'no cost' starting point in incorporated to encourage students and organisations to rethink assumptions that environmental improvement is costly and research simple starting interventions that are able to be implemented in all sizes of organisation to extend and provoke environmental responsibility within silent and ad hoc environmental actors.

\section{The EVFM Framework}

The EVFM Framework provides the students and educators a LTA tool that comprises the core of the module assignment and facilitates in-class activities and independent study that can enhance formative and summative feedback. It also, perhaps most importantly, provides a tool that students can use to demonstrate their environmental skills and knowledge within their future workplaces and promote a new, value for money, 'no cost' approach to environmental management and minimising climate impacts. 
The framework captures the current costs of facilities and operations that have an environmental impact in the 'Environmental Activity' column. Evidence-based improvement interventions are then proposed and recorded as a 'Saving Measure' along with their financial benefits (shown as a positive cost) and implementation costs (shown as a negative cost). Over the five-year period of the strategy the interventions and actions combine to form a selffunded environmental management strategy.

The EVFM Framework captures and evaluates improvement opportunities against the benchmark of the current activity cost to demonstrate the cost saving available from each improvement intervention and the long-term cost and environmental benefits of the initiative implemented. Savings achieved against the current operating cost (for students this is calculated from information provided in their case study brief) during each year are identified and balanced to create the total for the year. This savings total is then transferred to the following year's 'Environmental Fund at the start of the year', to create the investment budget for costlier and more impactful improvement interventions. The savings raised in each year do not have to be spent in the following year; budget surpluses can accumulate over the current strategy period. In practice, a planned surplus could also be deliberately built up and carried forward into future strategy periods to allow high cost interventions to be funded. As the EVFM Framework generates a self-funded environmental strategy, the Environmental Fund starting balance is zero by design.

Although the EFVM Framework captures the benefits of environmental improvement interventions and efficient utilisation of resources as financial savings, the authors recognise that these could also convert into environmental impact savings such as reduced carbon emissions or water consumption reduction. Financial parameters are adopted, as organisations are most likely to change practices if they can benefit financially (Hillary and Burr 2011). The financial savings achieved in the environmental management strategy example presented below highlight the value offered by the self-funding approach to environmental performance improvement through the EVFM Framework, particularly for financially constrained organisations

\section{Cost Effective Environmental Management Strategy}

Figure 1 contains an example of a self-funded, cost effective environmental management strategy generated through the EVFM Framework. This example, taken from a student's assignment, utilises the material provided in the company brief and the additional information obtained through participating in the audit meeting.

Environmental performance improvement interventions are included in the example presented to demonstrate the process and positive outcomes of this self-funded approach to minimisation of climate impacts. The EVFM Framework in Figure 1 includes short descriptions of the actions proposed; additional details are included below, along with benefit calculations and some analysis tools presented in class. These provide students a sense of agency in their strategy design and are of use to organisations adopting this strategic approach to environmental performance improvement. The environmental management strategy presented here highlights the learning available from this innovative approach to EfS and the potential financial benefits emanating from environmental impact minimisation for real-world organisations. 


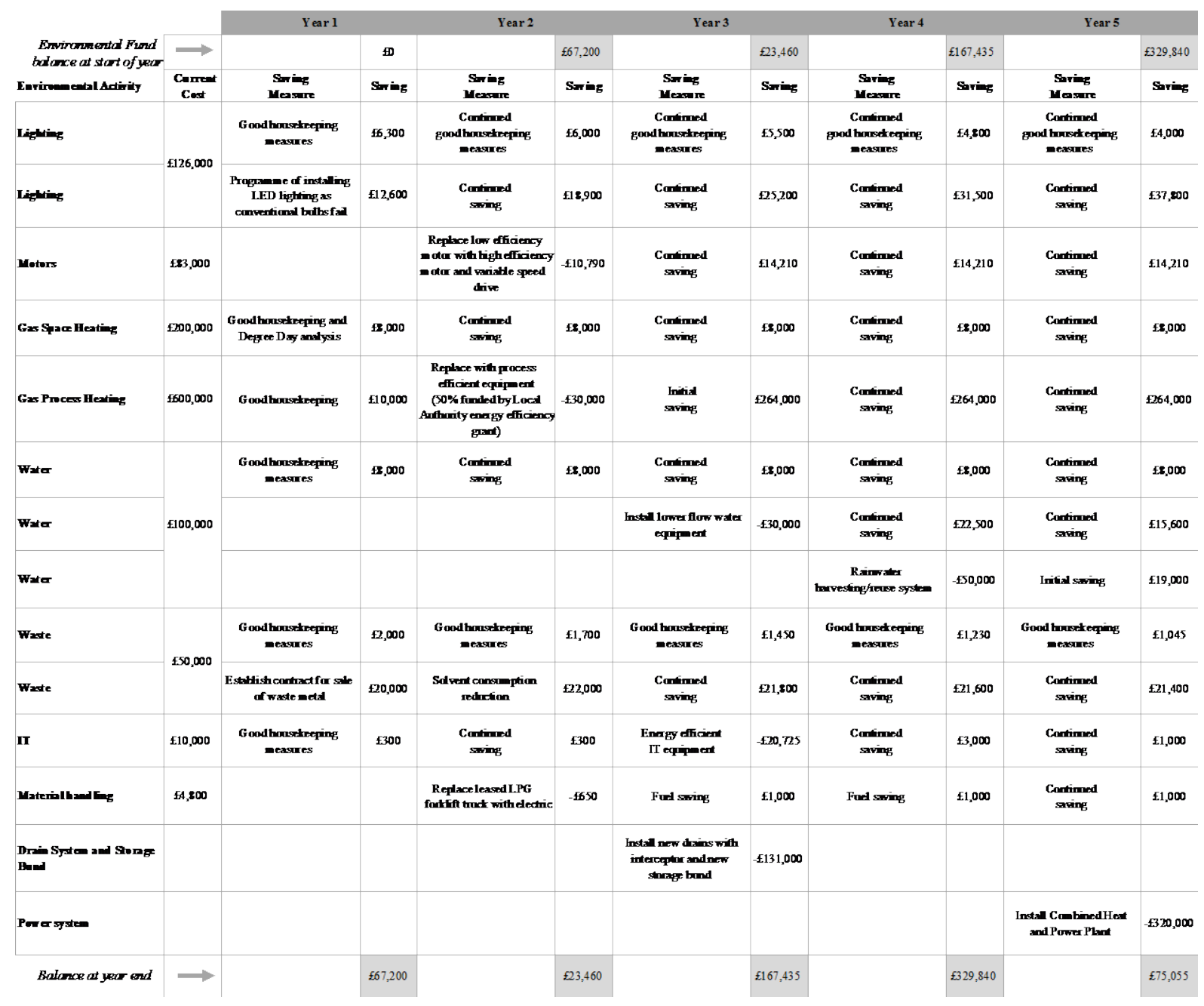

Figure 1: Environmental Management Strategy created through the EVFM Framework

\section{Self-funded Environmental Management Strategy in Practice}

1. Energy consumption reduction: Good housekeeping

Implementing good housekeeping is an effective intervention that can introduce long term 'no cost' behavioural change. Switching off unwanted heating, lights, production equipment and IT, closing windows, etc. could reduce consumption of electricity by $30 \%$ (Carbon Trust 2011). In addition, ensuring effective control of the heating system (the heating is gas powered in the simulated company) can reduce energy consumption. For example, reducing building temperatures by $1^{\circ} \mathrm{C}$ can reduce heating costs by $8 \%$ (Carbon Trust 2011). Good housekeeping continues in all years within this strategy. The financial benefit of energy efficient lighting reduces year-on-year as the lighting gradually changes to LEDs (see subsequent intervention).

2. Energy consumption reduction: Lighting. 
Traditional energy inefficient lighting within the workplace represents approximately $20 \%$ of total electricity consumption (Carbon Trust 2015). Conventional light bulbs are extremely energy intensive compared to fluorescent tubes and Compact Fluorescent Bulbs (CFBs). European Directive 2005/32/EC is phasing them out. Despite being costlier, lighting systems integrating Light Emitting Diodes (LEDs) offer significant longer-term financial benefits; LED lighting can use 50\% less energy than fluorescent tubes or CFBs (Carbon Trust 2015). However, as they are up to 300\% more expensive than fluorescent bulbs and CFBs (Carbon Trust 2015) and require different light fittings a cost-efficient short-term strategy would be to replace CFBs as they fail. The strategic priority would be to generate the investment required to install LED light fittings through the good housekeeping measures identified above. Since CFBs and fluorescent tubes have a long life this process may continue for several years and this is computed in the spreadsheet.

\section{Energy consumption reduction: Gas}

The simulated company is energy intensive and consumes high levels of gas for space heating and within manufacturing operations. However, the company brief does not specify individual gas consumption of these two applications. To investigate gas utilisation a Degree Day Analysis can be conducted which apportions total gas consumption to heating and operational processes. 'Degree Days' is a measure of the difference between the base heating temperature and the actual outdoor temperature multiplied by the number of days. In the UK the base temperature used to calculate Degree Days in the UK is $15.5^{\circ} \mathrm{C}$, because at this temperature most UK buildings do not need supplementary heating. If the outside air temperature drops below the heating base temperature, the building needs heating. The findings of the Degree Day Analysis can promote the prioritisation of improvement actions against the largest area of expenditure. To explore this further, and assist other educators and businesses to introduce the self-funded environmental management strategy approach, a Degree Day Analysis utilising the figures from the company brief, along with its strategic implication, is presented below.

Figure 2 shows the gas consumption and Degree Day figures for the simulated company over a 12-month period. When displayed graphically in a plot of gas consumption against Degree Days and a trendline added (Figure 3), the intercept value on the Y-axis identifies the process energy requirement. In this example operational processes consume 853, $891 \mathrm{kWh}$ of gas per month or $10,247,000 \mathrm{kWh}$ of over a 12-month period as annually. Subtracting the process requirement from the total energy consumption establishes the energy required for the company's space heating; in this example 3,117,000 kWh of gas is required annually for space heating and 10,247,000 kWh for operational processes.

Within a cost effective, self-funded environmental management strategy, a Degree Day Analysis can highlight where improvement actions should be prioritised. In this example the operational processes consume over three times the quantity of gas used for space heating, therefore improvement actions should focus here initially to reduce consumption and maximise contributions to the Environmental Fund. In years 2-4 when funding may be available for additional potential improvements, the Degree Day Analysis suggests that it would be more cost effective, and obtain greater returns, to invest in process efficiency prior to improving space heating.

$\begin{array}{lcc}\text { Consumption } & \text { Gas } & \text { Degree } \\ \text { period } & \text { consumption } & \text { Day Value }\end{array}$


$\mathrm{kWh}$

$\begin{array}{lcc}\text { January } & 1315433 & 402 \\ \text { February } & 1372222 & 415 \\ \text { March } & 1351111 & 362 \\ \text { April } & 1123111 & 230 \\ \text { May } & 1013333 & 140 \\ \text { June } & 823333 & 15 \\ \text { July } & 844233 & 0 \\ \text { August } & 848877 & 0 \\ \text { September } & 962666 & 35 \\ \text { October } & 1076667 & 160 \\ \text { November } & 1245556 & 280 \\ \text { December } & 1387000 & 325 \\ \text { Total } & \mathbf{1 3 3 6 3 5 4 4} & \mathbf{2 3 6 4}\end{array}$

Figure 2: Gas Consumption and Degree Days

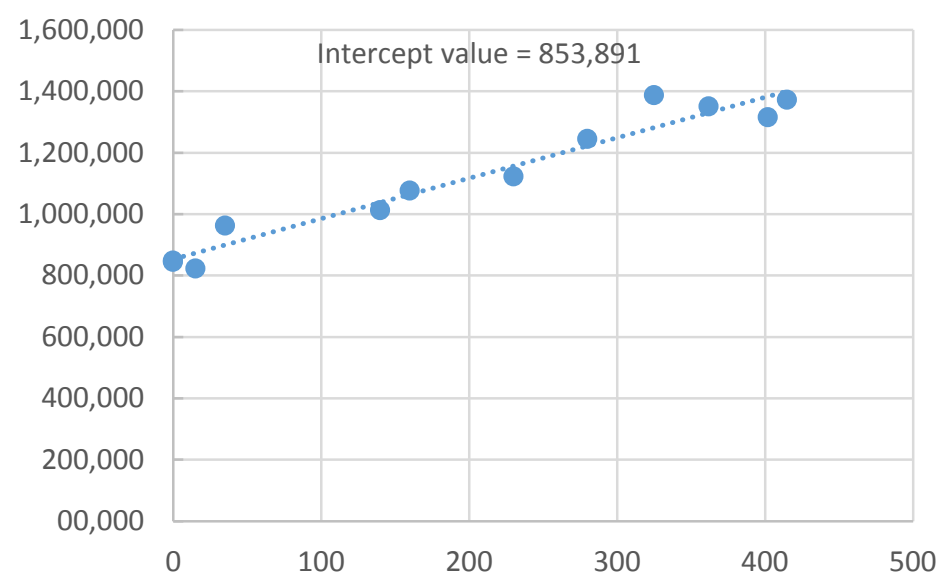

Figure 3: Correlation between gas consumption and Degree Days

The authors recognise that whilst this analysis tool only provides an estimate of the consumption of energy they recommend utilising it as a strategy development tool to create a baseline of organisational energy use from which to benchmark the impacts of energy efficient interventions on energy consumption.

\section{Motors}

Electric motors consume up to 70\% of industrial electricity (Gynther et al. 2016), yet many of those utilised remain relatively inefficient despite European Directive 640/2009 implementing mandatory efficiency levels for new electric motors. The application of a motor also determines its' energy consumption; many are wastefully operated at full output, rather than matched to the load.

In this strategy the Environmental Fund generated within Year 1 finances the replacement of the ten standard motors identified in the company brief with high efficiency units. These are to be operated via variable speed drives which helps to match the output to the load to 
maximise efficiency (Saidur 2010). Subsequent savings achieved from operating the new motors efficiently can reduce energy consumption and generate cost savings of c. $20 \%$ (Chan and Kantamaneni 2015).

\section{Water consumption reduction}

The company brief indicates there is a high operational water consumption, so that simple housekeeping measures make a small but nonetheless valuable contribution to financial savings. Carbon Trust (2015) suggest savings of 15\% are possible through no cost interventions. However, once there is sufficient investment available in the Environmental Fund, the strategy proposes the installation of low flow equipment and a rainwater harvesting system. Efficient use of these high cost interventions will deliver a significant reduction in water consumption and generate financial savings of up to 30\% (Envirowise 2016).

\section{Waste reduction}

The company brief indicates the simulated company sends 40 tonnes of mixed waste to landfill per year. Incorporating the current landfill tax of £86/tonne for general waste and $£ 200 /$ tonne for hazardous waste (Gov.uk 2017) with waste removal costs can generate the baseline cost of waste produced. The suggested strategic priorities are the sale of waste metal and adoption of good housekeeping measures to maximise reuse and waste reduction. These simple 'no-cost' housekeeping and behaviour changes can reduce waste by at least $15 \%$ (DEFRA 2011). Annual reductions in savings apportioned over the life of the strategy are included to reflect the reduction in volumes of waste generated.

\section{Material handling}

The environmental improvements to material handling equipment, replacing the LPG powered forklift truck identified in the company brief with an electric alternative increases the rental costs by c. 25\% (Anon 2017). However, this intervention generates overall savings as the reduced running costs of c. $40 \%$ offset the increase in rental charges. These savings prime the Environmental Fund and are used to invest in larger water consumption reduction interventions.

\section{Power generation system}

Within the environmental management strategy, investment in interventions that make operational processes' more energy efficient are prioritised as these processes consume a higher amount of gas than space heating. In year 5, when the Environmental Fund has sufficient budget, investment in a combined heat and power (CHP) plant is suggested. This would supply both heat and power to the organisation and offers considerably more efficient overall use of fuel than generating them individually. Despite the capital cost of $£ 310,000$ (Renewable Energy Hub 2017) energy consumption reduction could generate savings of c. $£ 60,000$ per year, as a CHP system requires c. 33\% less fuel to generate the same amount of heat and power (Northern Ireland Environment Agency 2017). This can therefore generate financial savings of c. $20 \%$ in the future strategy period.

9. Drainage system and storage bund 
Improvements to the drainage system and hazardous materials storage are examples of measures that can help to avoid environmental damage but not directly save money. A clearly recorded drainage system, incorporating an interceptor to remove oils and sediments from storm water and spills will protect water resources. In addition, the strategy suggests bunds are employed to offer secondary containment during the storage of hazardous materials and so further protect the environment. Whilst these interventions do not directly generate cost savings they will reduce environmental risk and the consequent threat of financial penalties and provide evidence to stakeholders of environmental responsibility. They also contribute to potential future opportunities to recycle and reuse waste water in the next strategy period.

\section{Impact and Implications of the Strategic Approach to Environmental Management Utilising the EVFM Framework}

The authors believe that organisational environmental performance improvement does not need to be costly or divert scarce resources from alternative operational requirements. This belief has led to the creation of the self-funded approach to environmental management strategy development presented in this paper, which has the EVFM Framework at its heart. Adopting this as a LTA methodology may be of use to others educators looking to incorporate active learning into business strategy or a practical approach into EfS. It may also be valuable for organisations seeking 'no cost' environmental improvement opportunities or a self-funded environmental strategy.

The EFVM Framework offers an environmental improvement tool that promotes environmental sustainability literacy, develops employment skills within the experiential, interactive learning environment advocated by HEFCE (2013) and Higher Education Academy (2016), and has re-fashioned EfS within Coventry University's Environmental Strategy Module. This can promote relevant employment skills for all learners, which contributes to the achievement of SDG 4 and provokes awareness raising and education advocated by SDG 12 .

The framework can engage students in generative sustainability through their preferred experiential, active learning style in a real world setting advocated by Oblinger and Oblinger (2005) and Wiek (2014). Students appear to find this learning, teaching and assessment approach challenging, as they must engage in generative sustainability to develop a creative innovative 5-year environmental management strategy. This assessed environmental management strategy is valuable, as it requires students to analyse the company brief and audit meeting information, undertake independent research and develop a customised strategic approach that is not available from the internet or within previous research papers. This level of challenge is however, considered appropriate for postgraduate students.

The LTA approach presented in this paper also offers many opportunities for educators to provide ongoing formative feedback and support. The in-class activities such as audit meetings, quizzes and informal presentations link theory and practice to the audit and environmental strategy to develop sustainability literacy and challenge students' thinking, which can develop learning for insight, considered valuable by Beech and MacIntosh (2012).

The authors suggest that incorporating an environmental management strategy into LTA disguises their intention to generate a long-term transformation of students' knowledge, skills and values, which is required to achieve sustainable futures and develop students' awareness and confidence (Harvey and Green 1993). As overt transformative learning appears unpopular with students, concealing this within a series of preferred short-term successes (Sharp 2012) through the audit, development of environmental management strategy 
components and self-directed learning can covertly develop knowledge and skills. Utilising a cost effective environmental management strategy as a LTA tool can also enhance the integrated thinking required for sustainability literacy, advocacy and employment skills (Ferreria, Lopes and Morais 2006) and contribute to an individual and collective sense of responsibility (Burgess 2006; Ellison and Wu (2008).

The EVFM Framework promotes both hard and soft employment skills demanded by students and their future employers (Pegg et al. 2014). Incorporating the framework into both teaching and assessment allows educators to encourage the development of student's personal values and support the development of their confidence in the inherent complexity of environmental management problems and solutions. This can contribute to closing the environmental skills gap identified by IEMA (2014) and Viegas et al. (2016).

Undertaking an audit and designing an environmental management strategy allows students to embed awareness of environmental sustainability issues, impacts and potential solutions by collating and synthesising information obtained in class and through individual assignment research to create knowledge (Nonaka 1994). This engages students in understanding organisations' environmental performance and develop strategic responses that are vital for sustainability advocacy and successful future careers rather than simply engaging in just-intime learning. The environmental audit of a simulated real-life company, also presents an opportunity to develop students' knowledge and experience of developing integrated solutions, which Ferreira, Lopes and Morais (2006) suggest will assist them appreciate the different dimensions and complexity of environmental problems.

Students participating in the Environmental Strategy Module are exposed to an environmental management technique that can feed forward into their future (or current) workplaces. This contributes to the achievement of SDG 4 as students leave Coventry University with relevant skills for employment and the knowledge and skills needed to promote sustainable development advocated by United Nations (2017). The authors' selffunded strategic approach to minimising climate impacts has already proven to be successful; one part-time student utilised the EVFM Framework in his employer's car component manufacturing company and generated a saving of $£ 300,000$.

Although the perception of investment may act as a barrier to formal environmental management (Ervin et al. 2012), the authors suggest that a self-funded environmental management strategy utilising initial 'no-cost' interventions can overcome this barrier and create sufficient funds to allow costlier improvements to be financed. The EVFM Framework offers this 'no cost' route into formal, strategic environmental management for organisations that have previously resisted environmental performance improvement, as they perceived they lacked financial resources to fund investments. The concept of an environmental management strategy based on a dedicated Environmental Fund is valuable as it demonstrates to organisations that they can make substantial improvement to satisfy stakeholders' demands for environmental responsibility (Cassells and Lewis 2017) without incurring upfront costs or funding interventions from existing budgets allocated for operational priorities. The incorporation of an environmental audit to provide the baseline performance appraisal, from which to develop an environmental management strategy, may also encourage sustainability reporting within organisations as advocated by SDG 12 (United Nations 2017).

Stimulating environmental responsibility through the EFVM Framework, which provides the structure for a management strategy and offers a systematic approach to improving sustainability performance whilst improving economic performance (Viegas et al. 2013) contributes to the achievement of SDGs 9 and 12 at local, corporate, regional, national and international levels. As students come from Coventry, the wider West Midlands, UK and 
Europe as well as well as Africa, Asia, and the Americas to study at Coventry University, the EVFM Framework and the self-funded approach to promoting environmental awareness and enhancing environmental responsibility can have worldwide reach.

\section{Conclusion}

The drive for sustainable futures requires more integrated and practical solutions that engage future sustainability professionals in constructive actions rather than reactive resolutions. The cost effective environmental management strategy presented offers a self-funded, proactive and accessible response to environmental challenges that can contribute to the development of environmental responsibility within individuals and businesses and the mitigation of climate change through the reduction in energy consumption, prevention of pollution and prudent use of natural resources.

This paper has presented a conceptual study of the authors' innovative cost effective and selffunded approach to environmental management strategy development that positions the EVFM Framework at the heart of the development process. This environmental strategy development approach has two purposes; firstly, it provides a LTA methodology that can develop students' sustainability literacy, skills and values in a real world setting that can contribute to the closure of current environmental skills gaps whilst engaging students' in experiential learning. Secondly, the carefully planned, economically viable strategic approach to environmental performance improvement can offer businesses a route to develop costeffective environmental responsibility. Evidence from a former student suggests this framework can feed forward to provoke the development of an environmental management strategy within students' workplaces. This environmental management strategy approach and framework may therefore be of value for both educators in the sustainability community seeking a practical methodology for EfS that encourages students' long-term transformation to successful environmental practitioner and sustainability advocate, rather than simply delivering just in time learning supporting (thus SDGS 4 and 12) and organisations seeking 'no cost' environmental improvement opportunities.

The authors recognise that this paper presents a conceptual study of the innovative strategic, self-funded environmental management approach and framework for both LTA and organisational development. The EVFM Framework's current focus on financial benefits of environmental interventions offers a single motivator for business improvements. However, incorporating environmental impact savings measured as reductions in carbon emissions, water use or waste generated may provide an additional driver for change.

Additional research into its applications and outcomes can validate its effectiveness for EfS and ability to promote businesses' environmental improvement practices that will contribute to the mitigation of climate change. The authors suggest undertaking an exploration of students' engagement with the EVFM Framework to test whether it can generate environmental insight and deeper learning to develop the sustainability literacy, knowledge, skills and values that are required to promote sustainable futures. Testing the EVFM Framework within businesses could validate commercial applicability and overcome perceptions that environmental interventions are cost consuming rather than cost saving.

\section{REFERENCES}


Anonymous (2017) Fork Lift Truck Hire. http://www.bendigomitchell.com/forklifts-for-hire/ (Last Accessed 19 Sept 2017)

Beckett R, Murray P (2000) Learning by auditing: a knowledge creating approach, The TQM Magazine. 12(2):125-136

Beech N, MacIntosh R (2012) Managing Change: Enquiry and Action, Cambridge University Press, Cambridge, United Kingdom.

Benn S, Dunphy D (2009) Action research as an approach to integrating sustainability into MBA programs: an exploratory study. J Manag Educ 33(3):276-95.

Burgess J (2006) Blogging to Learn, learning to blog. In: Bruns A Jacobs J (eds) Use of blogs. New York Peter Lang Publishers pp 91-103

Campos L (2012) Environmental management systems (EMS) for small companies: a study in Southern Brazil L Clean Prod 32:141-148

Carbon Trust (2011) Heating Control: Maximising comfort, minimising energy consumption. https://www.carbontrust.com/media/10361/ctg065_heating_control.pdf (Last Accessed 14

Sept 2017)

Carbon Trust (2015) Guidance Note 10: Lighting - Energy Technology List.

https://www.gov.uk/government/uploads/system/uploads/attachment_data/file/474456/Lighti ng_Guidance_Note_November_2015.pdf. (Last Accessed 14 Sept 2017)

Cashian P, Clarke J, Richardson M (2015) Perspectives on: Employability. Is it time to move the employability debate on? Chartered Association of Business Schools:

https://charteredabs.org/wp-content/uploads/2015/06/Employability-Debate1.pdf. (Last

Accessed 13 Sept 2017)

Cassells S, Lewis K (2017) Environmental management training for micro and small enterprises: the missing link? JSBED 24(2): 297-312

Chan Y, Kantamaneni R (2015) Study on Energy Efficiency and Energy Saving Potential in Industry and on Possible Policy Mechanisms. ICF International, Brussels

Clark G (1998) Maximising the Benefits from Work-based Learning: The effectiveness of environmental audits. JGHE 22(3):325-334

Conole G, Alevizou P (2010) A literature review of the use of Web 2.0 tools in higher education. York: Higher Education Academy. http://www.heacademy.ac.uk/

Corcoran P, Wals A (2004) Higher Education and the Challenge of Sustainability:

Problematics, Promise, and Practice. Boston: Kluwer Academic Publishers.

Crosthwaite C, Cameron I, Lant P, Litster J (2006) Balancing curriculum processes and content in a project centred curriculum: In pursuit of graduate attributes. Educ Chem Eng 1(1):39-48

Dewey J (1916) Democracy and Education; An Introduction to the Philosophy of Education, New York: Macmillan

DEFRA (2011) The Economics of Waste and Waste Policy. https://www.gov.uk/government/uploads/system/uploads/attachment_data/file/69500/pb1354 8-economic-principles-wr110613.pdf (Last Accessed 19 Sept 2017)

Drayson R (2014) Employer attitudes towards, and skills for, sustainable development Higher Education Academy. https://www.heacademy.ac.uk/system/files/executive-summaryemployers.pdf (Last Accessed 14 Sept 2017) 
Ellison, N. and Wu, Y. (2008). Blogging in the Classroom: A Preliminary Exploration of Student Attitudes and Impact on Comprehension. JEMH 17(1):99-122

Envirowise (2016). Reduce your water use and collect the savings.

http://www.wrap.org.uk/sites/files/wrap/EN847_final.pdf (Last Accessed 18 Sept 2017)

Ervin D, Wu J, Khanna M, Jones C, Wirkkalas T (2012) Motivations and Barriers to Corporate Environmental Management. BSE 22:390-409

European Environment Agency (2015) The European Environment - State and Outlook 2015. https://www.eea.europa.eu/soer (Last accessed 28 Oct 2017)

Ferreira A, Lopes M, Morais J (2006) Environmental management and audit schemes implementation as an educational tool for sustainability. J Clean Prod 14: 973-982

Finke T, Gilchrist A, Mouzas S (2016) Why companies fail to respond to climate change: Collective inaction as an outcome of barriers to interaction. J Ind Mar Man. 58: 94-101

Fothergill J, Smith D, Payne R (2017) Driving Sustainable Resource Management through ISO 14001. https://www.iema.net (Last Accessed 15 Sept 2017)

Gov.uk (2017) Waste costs. https://www.gov.uk/green-taxes-and-reliefs/landfill-tax (Last Accessed 18 Sept 2017)

Graafland J, Smid H (2016) Environmental Impacts of SMEs and the Effects of Formal Management Tools: Evidence from EU’s Largest Survey. Corp Soc Resp Env Ma.

23(5):297-307

Gynther, L., Mustonen, S. and Saarivirta, E. (2016). Policies and Measures for Promoting Efficient Electric Motors in Industry. https://wec-policies.enerdata.net/Documents/casesstudies/WEC-case-study-Electric-motor.pdf (Last Accessed 19 Sept 2017)

Harvey L, Green D (1993) Defining quality. Assess Eval High Educ. 18(1): 9-34

Higher Education Academy (2016) Higher Education Academy frameWORKS, 04 Essential frameworks for enhancing student success. http//www.heacademy.ac.uk/transform (Last Accessed 16 Sept 2017)

HEFCE (2013) Sustainable Development in higher education: consultation on a framework for HEFCE. Higher Education Funding Council for England. http://www.hefce.ac.uk (Last Accessed 16 Sept 2017)

Hillary R (2004) Environmental management systems and the smaller enterprise. J Clean Prod. 12(6):561-569

Hillary R, Burr P (2011) Evidence-based Study into the Benefits of EMSs for SMEs. http://www.randd.defra.gov.uk/Document.aspx?Document=FINALEV0440report.pdf (Last Accessed 19 Sept 2017)

IEMA (2014) Preparing for the Perfect Storm. https://www.iema.net/ (Last Accessed 15 Sept 2017)

Khalili N, Duecker S (2013) Application of multi-criteria decision analysis in design of sustainable environmental management system framework. J Clean Prod. 47:188-198

Lambrechts W, Ceulemans K (2013) Sustainability Assessment in Higher Education. Evaluating the Use of the Auditing Instrument for Sustainability in Higher Education (AISHE) in Belgium. In: Caeiro, S., Leal Filho, W., Jabbour, C., Azeiteiro, U. (Eds.). Sustainability Assessment Tools in Higher Education Institutions. Mapping Trends and Good Practice Around the World. Switzerland. Springer International Publishing. 
Large C (2012) ISO14001: Loved by procurement, hated by SMEs.

https://www.theguardian.com (Last Accessed 15 Sept 2017)

Laurinkari J, Tarvainen M (2017) The Policies of Inclusion. London. EHV Academic Press.

Moalosi R, Molokwane S, Mothibedi G (2012) Using a Design-orientated Project to Attain Graduate Attributes. Design and Technology Education. 17(1):30-43

Northern Ireland Environment Agency (2017) Combined Heat and Power (CHP) benefits and opportunities for business. http://www.netregs.org.uk/environmental-topics/carbon-reductionand-efficiency/combined-heat-and-power-chp-benefits-and-opportunities-for-business/(Last Accessed 15 Sept 2017)

Nonaka I (1994) A Dynamic Theory of Organizational Knowledge Creation. Organ Sci 5(1):14-37

Oblinger D, Oblinger J (2005) Educating the Net Generation. https://www.educause.edu/ir/library/pdf/pub7101.pdf (Last Accessed 15 Sept 2017)

Panwar R, Nybakk E, Hansen E, Pinkse J (2016) The effect of small firms' competitive strategies on their community and environmental engagement. J Clean Prod. 129:578-585

Pegg A, Waldock J, Hendy-Isaac S, Lawton R (2012) Pedagogy for employability. https://www.heacademy.ac.uk/system/files/pedagogy_for_employability_update_2012.pdf (Last Accessed 15 Sept 2017)

Potoski M, Prakash A (2004) The Regulation Dilemma: Cooperation and Conflict in Environmental Governance. Public Adm Rev. 64(2):152-163

Renewable Energy Hub (2017). Micro Combined Heat and Power Microchip CHP Information. https://www.renewableenergyhub.co.uk/ (Last Accessed 19 Sept 2017)

Saidur R (2010) A review on electrical motors energy use and energy savings. Renew Sust Energ Rev. 14(3):877-898

Sharp L (2012) Green campuses: the road from little victories to systemic transformation. IJSHE. 3(2):128-145

Shrivastava P, Shrivastava P (1995) The role of corporations in achieving sustainability. Acad Manag Rev. 4:936 - 960

Studer S, Tsang S, Welford R, Hills P (2008) SMEs and voluntary environmental initiatives: a study of stakeholders' perspectives in Hong Kong. Environ Plan. 51(2):285-301

UNESCO (2017). Education for Sustainable Development Goals Learning Objectives. http://unesdoc.unesco.org/images/0024/002474/247444e.pdf (Last Accessed 22 Sept 2017)

United Nations (2017). Sustainable Development Knowledge Platform: Sustainable Development Goals. https://sustainabledevelopment.un.org/sdgs (Last Accessed 22 Sept 2017)

Viegas C, Bond A, Duarte Ribeiro J, Selig P (2013) A review of environmental monitoring and auditing in the context of risk: unveiling the extent of a confused relationship. J Clean Prod. 47:165-173

Viegas, C, Bond A, Vaz C, Borchardt M, Pereira G, Selig P, Varvakis G (2016) Critical attributes of Sustainability in Higher Education: a categorisation from literature review. $\mathrm{J}$ Clean Prod.126:260-276 
Waddock S (2007) Leadership integrity in a fractured knowledge world. Acad Manag Learn Educ. 6(4):543-57

Wiek A, Xiong A, Brundiers K, van de Leeuw S (2014) Integrating problem-and projectbased learning into sustainability programs. IJSHE. 15(4):431-449

\section{Authors Biography}

Dr Kay Emblen-Perry has several years of senior environmental and ecology consultancy experience delivering consultancy projects in renewable energy technologies, contaminated land remediation, biodiversity offsetting and ecological assessment for UK organisations. She is qualified as an environmental and quality lead auditor, has implemented environmental management systems for both UK and multinational organisations and has trained environmental and quality assessors. In previous roles Kay gained senior project management and purchasing management experience in international automotive companies. She project managed the implementation of sustainable supply chain strategies, new vehicle projects and EU REACH Regulations. Kay's specialisation is in Sustainable Management including Environmental Management and Justice, Social Responsibility and Economic Sustainability.

Dr Les Duckers has been lecturing at Coventry University since 1975, initially in Physics and Engineering, later going on to establish the department of Environmental Sciences in 1992. Since then he has primarily taught masters course and supervised PhD students across a wide range of topics, reflecting his major research interest in environment and renewable energy, and especially wave energy. He is a visiting professor in Japan and Sri-Lanka and visiting lecturer to Reading and Loughborough Universities in the UK. He has experience of about 100 industrial environmental audits, is associate editor for The Renewable Energy Journal, and has acted as consultant to a number of companies. 